\title{
19. Yüzyıl Şairlerinden Sa'dullah İzzet ve Divanı
}

\section{ARZU ATÍK}

\author{
The 19th Century Poet Sa'dullah Izzet and His \\ Divan
}

\section{Ö Z E T}

19. yüzyıl her ne kadar batıl edebiyatm Osmanlıda başlangıcı olarak alınsa da bu yüzyılda klasik Türk şiir geleneğinin örnekleri verilmeye devam etmektedir. 19. yüzyılın ilk yarısında klasik anlayışla şiirler yazan şairlerden biri olan Müderris-zâde Sa'dullah $b$. Abdülkerim $b$. Mustafa Şeyhî 1206/1792 yılında Ankara'da doğmuştur. Hayatının büyük bir bölümünü Ankara ve civarında geçiren şair, Hacı Bayram-ı Velî̀nin (ö. 1429) soyundan Müderris-zâde Abdülkerim Efendi'nin oğludur. Sa'dullah Izzet, eğitimini tamamladıktan sonra Ankara'da naiplik yapmış, ardından İstanbul'a atandiğ $ı$ siralarda ilm- $i$ nücum eğitimi almıştır. Bu konuya ilgisi hayatı boyunca devam etmiş ve konuyla ilgili risaleler vermiştir. Sa'dullah Izzet'in nerdeyse her şiir türünden örnekler bartndıran hacimli bir divanı vardır. Torunu Mehmed Gâlib tarafından Sa'dullah İzzet'in ölümünden sonra tertip edilen bu divantn tek nüshası Millet Yazma Eser Kütüphanesi'nde bulunmaktadır. Ayrıca şairin divanının dışında Bayezid Devlet Kütüphanesi'nde kayitl olan mecmuasinda da şiirleri bulunmaktadır. Bu makalede Sa'dullah İzzet ve divanı tanıtılmaya çalışılacak, şiirlerinden örnekler verilecektir.

A N A H T A R K E L İ M E L E R

19. yüzyll, divan şiiri, Sa'dullah İzzet, ilm-i nücum, Ankara.

\section{A B S T R A C T}

19th century is accepted as the beginning of Western literature in the Ottoman Empire. However, examples of classical Turkish poetry is continued to be produced. Sa'dullah Izzet is a poet who lived in the first half of the 19th century. A big part of his life had passed around Ankara. Sa'dullah Izzet is the son of Müderris-zâde Abdülkerim who is Hacı Bayram-1 Veli's descendants. After completing his education, Sa'dullah Izzet was appointed as "naip" in Ankara. In Istanbul, he hasstudied "ilm-i nucum". This interest has continued throughout his life and gave "risale" on this subject. Sa'dullah Izzet has a"divan" that hasconsiderable volume. After his death, by his grandson Mehmed Galib, has arranged in a single copy of this "divan" that is located in the Millet Manuscript Library. This "divan" contains poems that are written with the concept of classic "divan" poetry. Also he has a "mecmua" that has his poemsin the Bayezid State Library. In this article, Sadullah Izzet will be introduced, and be given examples of poetry from his "divan".

\section{K E Y W O R D S}

19th century, divan poetry, Sadullah İzet, "ilm-i nücum" astrology, Ankara.

* Yard. Doç. Dr., İstanbul 29 Mayıs Üniversitesi, Türk Dili ve Edebiyatı Bölümü, İstanbul (arzuuatik@gmail.com). 


\section{GİRIŞ}

Birçok değişime gebe olan 19. yüzyıl, her alanda olduğu gibi edebiyatta da büyük kırılmaların meydana geldiği bir yüzyıldır. Batılı anlayışın hâkim olduğu bir edebî anlayışın yanı sıra klasik Türk şiirinin son örneklerinin verildiği de görülmektedir ama bunların daha önceki yüzyıllardaki şiir zevkini çok yansıtmadıkları söylenebilir. Özellikle hayal dünyasının zayıflaması, birbirine benzer şiirlerin çoğalması, "her şey" için şiir yazılması, "müteşâir"lerin artması 19. yüzyılda klasik şiirdeki bozulmanın yansımaları olarak görülebilir. Bu yüzyılda naiplik yapan, ilm-i nücumla uğraşan aynı zamanda edebiyatla ilgilenen Sa'dullah İzzet'in şiirleri de bu zevk çözülmesinin izlerini taşımaktadır. Bu makalede, merkezden uzak çoğunlukla Ankara ve civarında yaşamış Sa'dullah İzzet ve divanı tanıtılmaya çalışılacaktır.

1206/1792'de Ankara'da doğan Müderris-zâde Sa'dullah b. Abdülkerim b. Mustafa Şeyhî̀nin babası Hacı Bayram-ı Velî́nin soyundan Müderris-zâde Abdülkerim Efendi (ö.1813)'dir. Sa'dullah İzzet, medrese tahsilini tamamladıktan sonra naiplik görevine başlar. 1229/18141235/1819-20 tarihlerinde Ayaş ve Ankara'da naiplik yaptıktan sonra 1238/1823'te İstanbul'a, Sütlüce ve Hasköy'e naip olarak tayin olur. Aynı zamanda mühendishane hocası İshak Efendi'den hendese/hesapgeometri, Râkım Efendi ve Durak Paşa-zâde İbrahim Beg'den ilm-i nücûm öğrenir. 1240/1824-25'te tekrar Ankara'ya gelir. 1242/1826-27'de Ankara müftülüğü yapar. 1250-57/1835-41'de Ankara'da nüfus nâzırı olarak görev alır. 1257-62/1841-46'da sirasıyla Beypazarı, Kalecik ve Çankırı naipliğine atanır. Sonrasında naipliği bırakarak Ankara'ya yerleşen Sa'dullah İzzet, hocası İshak Efendi ve İstanbul'daki diğer devlet adamlarıyla da münasebetini kesmez ve arada İstanbul'a gider. Sa'dullah İzzet'in ilk eşi Nesibe Hanım'dan Mustafa Pertev adlı bir oğlu, ikinci eşi Âdile Hanım'dan Abdullah ve Necibe adında ikiz çocukları olmuştur. Sa'dullah İzzet, 1271/1855'te Ankara'da vefat eder."

\footnotetext{
* Bu paragraf, Gülçin Koç Tunalı tarafından Sa'dullah İzzet'in hayatının çok ayrıntılı ve titizlikle ele alındığı tezdeki kronolojik listeden istifade edilerek yazılmıştır. "Sa'dullah el-Ankaravî: Daily Concerns of an Ottoman Astrologer", Yüksek Lisans Tezi, İstanbul: Boğaziçi Üniversitesi, 2002, 143-44.
} 
Sa'dullah İzzet'in çoğunluğu Kandilli Rasathanesi Kütüphanesi'nde bulunan astronomi ve astroloji ile ilgili eserleri vardır: Cedvel-i İttisâlât-ı Kevâkib (Kut 2007: 52), Cedvel-i Mümâzecât-ı Kamer (Kut 2007: 55), Cedvel-i Teshîl-i Tahvîlât ve İttisâlât-ı Kevâkib (Kut 2007: 60) Cedvel-i Tesviyetü'lBuyût bi Sa'âti'l-Muvâfika (Kut 2007: 61-62), Mecmû'a-i Ahkâm (Kut 2007:432-33), 1220-66/1805-50 yıllarında çeşitli konularda yapılmış istihraçları içeren Zâyiçe Mecmû́ası (Kut 2007: 460); 1241-42 (Kut 2007: 256), 1229-30 ve 1238-68 (Kut 2007: 255) y1llarına ait Takvîm-i Sâl.

Ayrica Millet Yazma Eser Kütüphanesi, AE SRY 111'de kayıtlı Sa'dullah İzzet'e ait bir mecmua vardır. Bu mecmuada mektup suretleri; fetva ve hüccet suretleri; Arapça atasözlerinin şerhi; münazara risalesi; Hâfız, Kelîm, Şevket, Örfî, Sâ'ib, Vassâf şerhleri; Gelenbevî'nin Küsûrât-ı Hisâb adlı eseri, ayrıca konularına göre tasnif edilmiş çoğunlukla Farsça şiir örnekleri ve 301b'de Hacı Bayram-1 Velî́nin şeceresi de bulunmaktadır. Sa'dullah İzzet, şecerede kendi adının yanına bu mecmuayı toplayan ifadesini de eklemiştir.

Bu mecmuanın yanı sıra Sa'dullah İzzet'in muhtemelen birçoğunu kendi el yazısıyla kaydettiği şiirlerinden oluşan ve tek nüshası Bayezid Devlet Kütüphanesi 5749 numarada bulunan Evrâk-ı Perîşân Mecmû'a-i Eş'âr adlı bir mecmuası daha vardır. Bu mecmuada Sa'dullah İzzet'in alfabe sırasına göre gazelleri, ardından kaside ve tarihleri yer almaktadır. Bu gazellerin birçoğu bazı nüsha farklılıklarıyla birlikte divandakilerle ortaktır ama kaside ve tarihlerin çoğunluğu divanda bulunmamaktadır. Mecmuada aralarda farklı bir hatla Fuzûlî, Nef'î, Fazlî ve Şeyh Gâlib'in şiirleri de kaydedilmiştir. Mecmuanın 1a yüzünde 1280/1863 yılında bu mecmuanın Ankara'da Vahîd Efendi-zâde Ahmed Tevfik Efendi tarafından Seyyid Mehmed Tevfik Celalî̀ye hediye edildiğine dair bir kayıt vardır. Aralardaki farklı yazıyla kaydedilen şiirler muhtemelen Seyyid Mehmed Tevfik Celalî tarafından eklenmiş olmalıdır. Mecmuada ayrıca bazı risalelerden alıntılar yer almaktadır. 


\section{Sa dullah İzzet Divanı*}

Asıl konumuz olan Sa'dullah İzzet divanının Millet Kütüphanesi, AE MNZ 287'deki tek nüshası onun ölümünden sonra torunu Mehmed Gâlib tarafından tertip edilmiştir. Nüshanın başındaki yaprağın ön yüzünde güzel bir yazıyla Mehmed Gâlib yazılıdır. Üzerinde sayfa numarası "8" yazıl1"1a"yaprağında ise Fatin Davûd'un Tezkiresi'nden "Hâtimetü'l-eş'âr'da sahife 25" başlığıyla önce Sa'dullah İzzet'in oğlu Mustafa Pertev Efendi ve ardından Sa'dullah İzzet hakkında tezkiredeki bilgiler verilmiştir. Metnin alt kısmında iki Millet Kütüphanesi mührü, bir Ali Emiri vakıf mührü ve bir "Evkâf-1 Hümâyûn" mührü vardır.

Nüshanın şekilsel özelliklerine gelince rika ile kaleme alınmış olan eser, aradaki ve sondaki boş sayfalarla birlikte 382 sayfadır. Nüsha muhtemelen hazırlayan tarafindan 8'den itibaren sayfa sayısına göre numaralandırılmış, sonradan kurşunkalemle varak numarası verilmiştir. Nüsha ciltlenirken bir karışıklık sonucu bazı yapraklar yanlış sıralandığından tarafımızdan sayfa numaraları dikkate alınmıştır. Aralarda pek çok boş sayfa vardır. Krem rengi Avrupa kâğıda yazılmış, mukavva üzerine sırtı siyah bez, ebru bir ciltle ciltlenmiştir. Cildin ön kapağı sırttan ayrılmış, ön ve arka kapağının kenarları yıpranmıştır.

Divanın içeriğinde ise biri Farsça 16 kaside, biri mesnevi şeklinde 37 tarih, 4 murabba, 6 tahmis, 1 muhammes, alfabe sırasına göre dizilmiş, bazıları noksan 10'u Farsça yaklaşık 346 gazel, biri Farsça yaklaşık 34 kıta, 9'u Farsça 141 müfred, 2 lügaz ve 3 muamma vardır. Mehmed Gâlib tarafından bazı şiirlerin başında kırmızı mürekkeple "Evrâk-ı Perîşândan, Dîvân-1 nâ-tamâmdan, hezâr renc ü mihnetle bir hâinden, Nazif Efendi, İsmail Efendi marifetiyle" gibi ifadelerle şiirlerin nerelerden/kimlerden alındığı belirtilmiştir. Bu ifadelerden ayrıca nâ-tamam bir divanın da olduğu söylenebilir.

Sa'd, Sa'dullah ve İzzet mahlasını kullanan Sa'dullah İzzet'in divanı sayfa 9'da şu beyitle başlar:

Bak bu mecmû'ayı gördükde bir ehl-i dikkat

Dedi nâmına o dem defter-i derd-i ‘'̇zzet

\footnotetext{
*Divan, mecmuadaki şiirler de eklenerek tarafımızdan yayına hazırlanmaktadır.
} 
Ardından 13. sayfaya kadar münacat, şifa bulmak ve affedilmek için dua, naat içerikli şiirler vardır. 17. sayfa itibariyle klasik düzene uygun olarak kasideler başlar. İlk kaside Münîb Efendi'ye yazılmıştır. Ardından Abdurrahman Paşa'ya yazılmış 1ydiye ve ramazaniye gelir. Abdurrahman Paşa'yı övmek için yazdığı bu ramazaniyede, gazelde Nâbî'den "sihr-âferîn" olarak bahseder, kasidede üstat olarak Hassan ve Nef' ìnin $^{\prime}$ adını verir. Nef' î́nin onun kasidesini görse "Ben gittikten sonra meydan boş kalmamış" diyeceğini söyleyerek kendini över:

Gazelde Nâbî-i sihr-âferîn eder tahsîn

Kasîdede dahi Nef'î-le hazret-i Hassân

Eger kasîdemi Nef'î göreydi hamd ederek

Der idi ben gideli kalmamış tehî meydân (Divan s. 22, b. 39-40)

Abdurrahman Paşa'nın hazinedarı Ali Paşa için ramazaniye, şair Rüşdi Efendi'ye "sühan" redifli kaside, yine Abdurrahman Paşa için bahariye, üstadı Hayret Efendi'ye bir kaside, Şeyhülislam Ârif Efendi'ye memuriyet istemek için yazılmış bir kaside vardır. Bu kasidede Çankırı'da naiplik yaptığını ve Ârif Efendi'ye burada bir tarih takdim ettiğini, sonra da azledildiğini, şairler Arif Efendi'nin ihsanını alırken onun azledilmenin acısını çektiğini şu beyitlerle anlatır:

Bundan añla baña çarhıñ ne kadar hasm idügin

Akdemâ Kankırı'da nâ'ib iken abd-i kadîm

Sadrı teşrîf-i şerîfiñde berây-1 tebrîk

Âcizâne kuluñ etdim idi târîh takdîm

Şu'arâ zümresi alırlar iken ihsânuñ $51,53)$

Gam-1 azlile kuluñ oldum o dem azm-i remîm (Divan s. 36, b. 50-

Devaminda Gâlib Paşa için bahariye, sonrasında iki nâ-tamam fahriye vardır. Fahriyenin ilk beyti şöyledir:

Benim ol şâ‘ir-i mu'ciz-nefes ü Îsî-dem

Mürde-dil rûh bulur her ne zamân söylersem (Divan s. 38)

41. sayfadaki Sultan Mahmud'un övgüsü başlıklı, yeniçeriliğin kaldırılmasının anlatıldığı nâ-tamam 82 beyitlik bir kasidenin ilk beyti şöyledir: 
Feyz-i Hakkıñ hazret-i Mahmûd Hândır mazharı

Rûh-1 pâk-i seyyidü'1-kevneyn olmuş yâveri

Bu kaside Keçecizâde İzzet'in yine Sultan Mahmud'a yeniçerilerin ilgası hakkında Nef' '̂́'ye nazire olarak yazdığı aşağıda matla beyti alınan kasideye naziredir denilebilir:

Oldu zâhir mu'cizât-1 hazret-i peygamberî

Gördüler dünyâda kâfirler azâb-1 mahşerî (Ceylan 2005: 102)

51. sayfada "Tevarih" başlıklı bölüm başlar. İlk olarak mesnevi şeklinde Geredeli Derdli'nin 68 beyitlik tercüme-i hali ve 1262/1846 olan ölüm tarihi verilir:

Âh âşık Derdli göçdü rahmetullahi aleyh

Ölmeden evvel haber vermişdi kendin fevt-ile

Düşdü bir târîh-i cevherdâr Sa'dâ yaz hemân

Derd-i aşka buldu âşık Derdli dermân fevt-ile 1262/1846 (Divan s. 54)

Ardından amcaoğlu İsa Arif Efendi'nin yalıya nakline, Ali Fâik'in doğumuna, hekimbaşı Mesud Efendi'nin oğlu Necib Efendi'nin sakal bırakmasına, Mehmed Ağa'nın silahşorluğuna, Hâdî Efendi'nin tamir ettirdiği mescide, hazinedar Ali Ağa'nın yaptırdığı çeşmeye, Yiloğlu'nun ve Delibaş Gemalmaz'in ölümüne, Şehzâde Murad'ın doğumuna, Necib Efendi'nin ahi babalığına, Salim Efendi'nin mecmuasına, Tâceddin Dergâhı'nın tamirine düşürülmüş tarihler vardır. Bunların yanı sıra 1267/1850-51 tarihinde meydana gelen kuraklıktan sonra zahirenin bugünkü manasıyla karaborsaya düş̧üğü, yağan yağmurla kıtlığın biteceği ve vurguncuların meyus olacağına şükredilen tarih şöyledir:

Sâl biñ iki yüz altmış yedide sultânım

Oldu anbârda ecnâs-1 zahâyir mahbûs

Halk nânı kapışırken hele rahmet yagdı

Muhtekirler de o dem hamd ola oldu meyûs (Divan s. 61)

65. sayfada "murabba ve muhammes" başlığıyla ilk olarak bir muhammes, ardından Zekâyî Efendi'nin gazelini, ardından Şeyhî'nin beytini, Şeyh Gâlib'in gazelini tahmis, ardından iki murabba, sonra Hikmet'in Farsça gazelini Türkçe tahmis, bir murabba, bir muhammes, bir terkib- 
bend, bir murabba, Mazhar'ın Farsça gazelini Farsça tahmis ve son olarak Fuzûlî́nin gazelinin nâ-tamam bir tahmisi vardır. Bu tahmisin ilk bendi şöyledir:

Baña çok görmez iken çarh ol gül-i handânımı

İşiden ta'n etdi kûyunda olan efgânımı

Seyr eden dahl etdi çâk-1 sîne vü dâmânımı

Her gören 'ayb etdi âb-1 dîde-i giryânımı

Eyledim tahkîk görmüş kimse yok cânânımı (Divan s.73)

81. sayfadan itibaren eliften başlayarak gazellere geçilmiştir. Genelde çok ağır bir dil kullanmayan şairin gazellerinde aşk, şarap, sevgilinin güzelliği, felekten ve hak ettiği ilgiyi görememekten şikâyet gibi klasik şiirin konularının dışına çok fazla çıkmadığı görülür.

Gazellerden sonra 347. sayfada kitalar ve rubailer, 357. sayfadan itibaren ise müfretler başlar. Bu müfretlerden bazılarının mecmuadaki gazellerin matla veya makta beyitleri olduğu görülmektedir.

375. sayfada "Bazı mukâlemât" başlıklı bölümde şaire Azize Hanım'a hatır sormak için yazılmış üç beyit ve cevaben yazılmış altı beyit vardir.

379. sayfada ise lügaz ve muamma bölümü ilginç bir lügaz ile başlar. Bu on dört beyitlik lügaz lif içindir:

Gençliginde ne aceb pîr olmuş

Gece vü gündüz yedigi kir olmuş (Divan s. 372, b. 2)

Sağlığında divanını kendi tertip etmediğinden muhtemelen son defa Sa'dullah İzzet tarafından gözden geçirilme fırsatı bulunamamış şiirlerde yer yer vezin aksaklıkları ve tekrarlar görülür. Bazı şiirler ise tamamlanamamıştır. Divanda bunların başına "noksan" ibaresi konulmuştur.

Sa'dullah İzzet; Fuzûlî, Nef'î, Nâbî, Nedim gibi şairlerden etkilenmiştir. Aynı zamanda Hikmet, Gâlib Paşa, Yümnî, Nurî ve Keçecizâde İzzet'e de nazireleri vardır. Ama şairin, nazire yapmaktaki maksat olan tanzir edilen şiiri aşmaya, ondan daha iyisini söylemeye pek de ulaşamadığı kendi tarafından da söylenir. Aşağıda Yümnî'ye nazire olan gazelinin makta beytinde şair, kaleminin belagat meydanında "bî-tâb" olduğunu söyler: 
Edince İzzetâ Yümnî Bege tanzîrler teklîf

Kalem bî-tâb-1 meydân-1 belâgatdir düşer kalkar (Divan s. 177)

Bunun yanı sıra Nedim'in "Aşka düşdüm cân u dil müft-i cüvânân oldu hep /Sabr u tâkat masraf-1 çâk-1 girîbân oldu hep" (Macit 2012: 258) matlalı gazeline yazdığı nazire ise söyleyiş olarak güzel bir gazeldir:

Aşka düşdüm sîneden şevkim gürîzân oldu hep

Tâk-1 bünyân-1 sebâtim hâke yeksân oldu hep (Divan s. 97)

Sa dullah İzzet'in şiir anlayışına değinecek olursak aslında onun şiiri ve ilm-i nücûm'u Osmanlı uleması içinde varlığını sürdürebilmek ve bu zorlu yarışta oyunda kalabilmek için iki araç olarak (Tunalı-Koç 2002:47) kullandığı, özellikle mecmuadaki kasidelerinden ve zayiçe mecmuasından anlaşılabilir. Şiire bu açıdan baktığı tahmin edilen Sa'dullah İzzet'in şiirlerinden yüksek bir edebi zevk beklememek gerektiği söylenebilir. Divanda şair Rüşdî için yazdığı "sühan" redifli kasidesinde kendini ve diğer şairleri nasıl değerlendirdiği dikkate şayandır:

Âh efendim yalıñız ben degilim gaddârı

Var benim gibi niçe şâ' ir-i nâdân-1 sühan

...

Merhamet k1l müteşấ'irleri tekdîr etme

Olmasın biri dahi ya'nî perîşân-1 sühan

Gerçi terbiyyesi vâcib bu gürûhuñ zîrâ

Etmesinler ne ise bir dahi 'isyân-1 sühan ( Divan s. 25-26, b. 20, 2223)

Yukarıdaki beyitlerden de görüldügü üzere aslında şair, kendi gibi şair geçinenlerden bahseder ve bu güruhun terbiyesinin vacip olduğunu söyler. O asırda şiir cahili şairlerin bulunduğunu ve bunlardan birinin de kendi olduğunu söyleyecek kadar açık sözlüdür.

Bir gazelinin makta beytinde ise buna rağmen şiirinin şairler tarafından arandığını da söyler:

İzzetâ ol mertebe şi riñ selîs olmaz seniñ

Zümre-i şấ'ir niçineş'ârın eyler ârzû (Divan s. 310) 
Yukarıdaki beyitlerden de anlaşılacağı üzere şair, zaman zaman divan şiiri geleneğine uyarak kendi şiirini övdüğü beyitler yazsa da aslında kendi sınırlarının farkındadır denilebilir.

\section{Sonuç}

Klasik edebiyatın yavaş yavaş sahneden çekildiği 19. yüzyılda Ankara'da yaşamış Sa'dullah İzzet ve divanının tanıtıldığı bu makalede daha çok bürokratlarla muhatap olmuş bir şairin şiirlerine değinilmeye çalışılmıştır. Divanında neredeyse her nazım türünden örnekler veren Sa'dullah İzzet'in şiirlerinde yüksek bir edebi zevk bulunmadığı söylenebilir; ama gerek döneminin devlet adamlarına yazdığı şiirler gerek çeşitli olaylar, kişiler ve yapılar için düştüğü tarihler döneminin tarihine 1şık tutacak niteliktedir denilebilir. Divan ve mecmuadaki şiirlerin birlikte ele alınacağı bundan sonraki çalışmamızda 19. yüzyılda naiplik yapmış, ilm-i nücûm ile uğraşmış Ankaralı bir bürokratın şiir dünyası daha ayrıntılı olarak ortaya çıkacaktır kanaatindeyiz.

\section{Kaynaklar}

CEYLAN, Ömür ve Ozan YILMAZ(2005), Hazâna Sürgün Bahâr: Keçecizâde İzzet Molla ve Dîvân-ı Bahâr-ı Efkâr, İstanbul: Sahhaflar Kitap Sarayı.

KOÇ TUNALI, Gülçin (2002), "Sa'dullah el-Ankaravi: Daily Concerns of an Ottoman Astrologer", Yüksek Lisans Tezi, İstanbul: Boğaziçi Üniversitesi.

KUT, Günay, Hatice AYNUR, Cumhure ÜÇER ve Fatma BÜYÜKKARCI YILMAZ (haz.) (2007), Boğaziçi Üniversitesi, Kandilli Rasathanesi ve Deprem Araştırma Enstitüsü Kütüphanesi Astronomi, Astroloji, Matematik Yazmaları Kataloğu. Kandilli Rasathanesi El Yazmaları 1: Türkçe Yazmalar, İstanbul: Boğaziçi Üniversitesi, Elginkan Vakfı.

MACİT, Muhsin (haz.) (2012), Nedîm Dîvânı, Kültür ve Turizm Bakanlığ Kütüphaneler ve Yayımlar Genel Müdürlüğü.

http:/ / ekitap.kulturturizm.gov.tr/Eklenti/10635,nedim-divanipdf.pdf?0 (03.07.2014)

Sa'dullah İzzet, Dîvân-ı Sa'dullah İzzet, Millet Yazma Eser Kütüphanesi, AE MNZ 287. 


\section{Şiirlerinden Seçmeler}

\section{Bu dahi der-sitâyiş-i Velî Efendi}

$\ldots_{--} / ._{-} / ._{--} / ._{-}$

feilâtün/ feilâtün/ feilâtün/feilün

1 Kıldı bir zât-1 Hudâ husrev-i zî-şân-ı sühan Lây1k-1 saltanat u şevket-i 'unvân-1 sühan

2 Mülk-i nazmı aña teslîm edip Hâkânî Oldu erbâb-1 sühan hayline sultân-1 sühan

3 Na't-i pâk-i şehi kevneynini seyr etse eger Aña tahsîn eder hazret-i Hassân-1 sühan

4 Şu'arâ zümresiniñ oldu o şâhinşâhı Re'y-i sâ'ible olup şimdi cihânbân-1 sühân

5 İsm-i zâtına mutâbık ki Veliyyü'd-dîndir Mahlas-1 pâki de Rüşdî-i hünerdân-1 sühan

6 Tab's mecrâ-yı füyûzât-1 Hudâ oldukça Pür olur gonca-i nutkuyla gülistân-1 sühan

7 Gülşen-i fikretiniñ goncası şi'r $r$ ü inşâ Görünür kilk dahi serv-i hırâmân-1 sühan

8 Şu'arâ-yı selefi zinde eder şâyeste Ger devâtına desem çeşme-i hayvân-ı sühan

9 Nokta-i nazm[1] siyeh-hâl-i perî-rûlardır Lîk anı dâg-1 derûn etdi hasûdân-1 sühan

10 Hâfız [u] Sa'dîyi añdırdı efendim gazeliñ Eylemiş Hak saña bu mertebe ihsân-1 sühan

11 Fâzıl-1 pür-hüner âsâf-hamîrâ Mevlâ Eylemiş zât-1 simâtıñı kadir-dân-1 sühan

12 Sensiñ ol taht-nişîn-i hüner ü dâniş kim Yüz sürer dergehiñe sadr-nişînân-1 sühan

13 Ben de ahvâl-i dil-i zârımı 'arz eyleyeyim Bugün ey dâver-i ârâyiş-i dîvân-1 sühan

14 Edeyim izn-i şerîfiñle biraz sultânım Dergehiñde nice bir şekve vü efgân-1 sühan 
15 Bir münâsib söz içün hâmemi alsam elime Âşinâ sözler olur gûl-i beyâbân-1 sühan

16 Bir gazabla o zamân ben dahi ol elfâzıñ Eylerem her birini bir yere efşân-1 sühan

17 Anıñ içün baña bîgâne olandır ma'nî Gevher almaz dehenim olsa eger kân-1 sühan

18 Lutf edip diñleme feryâd ederlerse eger Bî-ser ü pâ biraz elfâz u perîşân-1 sühan

19 Çok zamândır ki şikâyet edeceklerdi velî Neylesinler yog-idi nükte-şinâsân-1 sühan

20 Âh efendim yalıñız ben degilim gaddârı Var benim gibi niçe şấir-i nâdân-1 sühan

21 Anlarıñ hâlini benden de efendim a'lam Bilir elbet fukarâsını emîrân-ı sühan

22 Merhamet kıl müteşâ‘ irleri tekdîr etme Olmasın biri dahi ya'nî perîşân-1 sühan

23 Gerçi terbiyyesi vâcib bu gürûhuñ zîrâ Etmesinler ne ise bir dahi 'isyân-1 sühan

24 Saçma gûyân-1 sühan böyle niyâz eylediler Bâb-1 lutfuñda bugün ey şeh-i zî-şân-1 sühan

25 İzzetâ hatm-i kelâm eyle de kıl gayrı du'â Ömr ü ikbâli mezîd ola ki sultân-1 sühan (Divan, s. 25-26, 5. Kaside)

\section{Bu dahi}

mefâ̂̂lün/mefâîüün/mefâîlün/mefâîlün

1 Saña her şeb kapıñda subha dek tevkîr eder mehtâb İsitmiş bezmi teşrîfiñ yoluñ tenvîr eder mehtâb

2 Degil encüm sipihriñ tâsını göz göz delip hâlâ Cihânıñ şehd-i nâbın süzmege kefgîr eder mehtâb

3 Sipihriñ rahne-yâb oldukça tâkı âh-1 âşıkdan Gece zerrîn hışt ile gelip ta'mîr eder mehtâb 
4 Dehân-1 goncada şebnem kıyâs etmekle gülşende

Olup süd annesi gûyâ ki şîr şîr eder mehtâb

5 Çıkarmış gâlibâ bir mihr-i hüsnüñ dâmenin elden

Degil hâle anı gözlük takıp tasvîr eder mehtâb

6 Kem ü bîşinde devrânıñ karâr olmadigın Sa'dâ

Çıkıp kürsî-i va'za ayda bir takrîr eder mehtâb (Divan, s. 98,20.Gazel)

\section{Dîvân-1 nâ-tamâmdan}

${ }_{-} \cdot /_{-} \cdot \cdot_{-} \cdot \cdot_{-} \cdot /_{-}$

mefûlü / mefâîlü / mefâîlü / feûlün

1 Ol şivve-reviş kad yine reftârına mahsûs

Reftâr-1 dilârâ yine etvârına mahsûs

2 Tahsîs edip 'uşşâkına düşnâm-1 cefâyı

Kılmış keremin zümre-i agyârına mahsûs

3 Fincâna muhassasdır anıñ leblerini bûs

Gerdânını hem turre-i tarrârına mahsûs

4 Gûş-1 dil ile meclise teşrîfin işitdim

Geldim o şehiñ lezzet-i güftârına mahsûs

5 Almış yine bir tîg-i cefâ destine ol şûh

Merdâne gelir 'İzzet-i gam-hvârına mahsûs (Divan, s. 229,177.Gazel)

\section{Bu dahi}

${ }_{-} \cdot / \cdot \cdot_{-} \cdot / \cdot \cdot_{-} \cdot / \cdot{ }_{-}$

mefûlü / mefâîlü / mefâîlü / feûlün

Kâmımca safâ görmemiş iken bu cihânda

İllet ile oldum iki yıldır hele cândan

Âlâm [u] keder etmededir kalbimi tahrîş

Ya Rabbî kerem kıl beni kurtar halecândan (Divan, s. 347, 10. K1ta)

\section{Dîger}

$-{ }_{-} \cdot / \cdot{ }_{-} \cdot / \cdot{ }_{-} \cdot / \cdot{ }_{-}$

mefûlü / mefâîlü / mefâîlü / feûlün

Bir lahzada biñ şekl-i garîb etmede peydâ

Dehr-i mütekallib ne aceb şu'bede-bâzdır (Divan, s. 357, 5. Müfred) 